\title{
(6) OPEN ACCESS \\ Surveillance of paediatric exposures to liquid laundry detergent pods in Italy
}

\author{
Laura Settimi, ${ }^{1}$ Felice Giordano, ${ }^{2}$ Laura Lauria, ${ }^{1}$ Anna Celentano, ${ }^{3}$ Fabrizio Sesana, ${ }^{3}$ \\ Franca Davanzo ${ }^{3}$
}

${ }^{1}$ National Centre for Epidemiology, Surveillance and Health Promotion, National Institute of Health, Rome, Italy ${ }^{2}$ Department of Public Health and Infectious Diseases,

Sapienza University, Rome, Italy ${ }^{3}$ National Poison Control Center in Milan, Niguarda Cà Granda Hospital, Milan, Italy

\section{Correspondence to}

Laura Settimi, National Centre for Epidemiology, Surveillance and Health Promotion, National Institute of Health Via Giano della Bella 34, Rome 00163, Italy; laura.settimi@iss.it

Received 27 October 2016 Revised 11 January 2017 Accepted 18 January 2017 Published Online First 8 February 2017

Check for updates

To cite: Settimi L, Giordano F, Lauria L, et al. Inj Prev 2018;24:5-11.

\section{ABSTRACT}

Objective To analyse paediatric exposures to pod and traditional laundry detergents in Italy and changes in exposure trends.

Methods Analyses of a series of patients aged $<5$ years and exposed to laundry detergents between September 2010 and June 2015, identified by the National Poison Control in Milan.

Results In comparison with patients exposed to traditional laundry detergents $(n=1150)$, a higher proportion of those exposed to pods $(n=1649)$ were managed in hospital (68\% vs $42 \%$ ), had clinical effects (75\% vs 22\%) and moderate/high severity outcomes $(13 \%$ vs $<1 \%)$. Exposure rates were stable over time for traditional detergents (average 0.65 cases/day), but an abrupt decline in major company pods was seen in December 2012, 4 months after the introduction of opaque outer packaging (from 1.03 to 0.36 cases/day and from 1.88 to 0.86 cases/million units sold). The odds of clinical effects was higher for exposure to pods than for traditional detergents $(O R=10.8 ; 95 \% \mathrm{Cl} 9.0$ to 12.9). Among patients exposed to pods, the odds of moderate/high severity outcomes was four times higher for children aged $<1$ years than for the other age groups $(\mathrm{OR}=3.9 ; 95 \% \mathrm{Cl} 2.2$ to 7.0$)$. Ten children exposed to laundry detergent pods had high severity outcomes while no children exposed to traditional laundry detergents developed high severity effects.

Conclusions The study confirms that exposure to laundry detergent pods is more dangerous than exposure to traditional detergents. In Italy, 4 months after the introduction of opaque outer packaging by a major company, product-specific exposure rates decreased sharply, suggesting that reducing visibility of laundry detergent pods may be an effective preventive measure. Further efforts are needed to improve safety.

\section{INTRODUCTION}

Liquid laundry detergent pods (LDPs) are unit dose fabric washing products consisting of about 32 $50 \mathrm{~mL}$ of concentrated liquid detergent wrapped in a water-soluble membrane. According to the International Association for Soaps, Detergents and Maintenance Products (AISE), these products are intended to improve environmental sustainability of liquid laundry detergent consumption by providing the correct dosage for washing needs and reducing packaging size. ${ }^{1}$ However, following their launch in the UK, Irish, and French markets in 2001, a few reports of paediatric poisonings and injuries highlighted the potential for these products to cause eye damage ${ }^{2-7}$ pulmonary and central nervous system toxicity ${ }^{5-10}$ and serious laryngopharyngeal injuries. $^{6} 11$ A decade later, these products were introduced into other national markets without considering the need for specific measures to prevent exposures. Consequently, these countries started to document cases of patients with LDP exposures presenting with severe respiratory, oesophageal, gastric, ${ }^{12-18}$ eye $^{19-21}$ and skin injuries, ${ }^{2-24}$ together with cases of altered mental status. $^{12} 13$ Studies based on large series of cases handled by Poison Control Centres (PCCs) or emergency departments confirmed that LDP-related cases are more likely to develop signs/symptoms and moderate/high severity clinical effects than those exposed to traditional laundry detergents (TLDs). ${ }^{20}$ 25-31

LDPs were initially launched in the Italian market in mid-August 2010; they were sold in seethrough outer packaging by a major company (MC) and 1 year later in the same way by other companies (OCs). In the days after the MC-LDPs launch, the National Poison Control Centre in Milan (NPCCMi) started receiving an increasing number of requests for toxicological assistance of young children exposed to laundry detergents and with unexpected respiratory and ocular effects. It became immediately evident that the observed events were associated with the new product. $^{22}$ Therefore, NPCCMi contacted the company manufacturing the product associated with the reported cases, AISE and the Ministry of Health to make the case for taking preventive measures. This alert initiated the monthly monitoring of exposures to laundry detergents by NPCCMi and the Italian National Institute of Health.

After considering the information provided about cases of exposure to LDPs, a series of voluntary initiatives were undertaken by the MC and OCs: in January 2011, the precautionary statement "keep out of reach of children", together with the corresponding icon, was introduced during MC-LDP television advertisements. Furthermore, the icon was made more prominent on the seethrough outer packaging. In January 2012, an additional opening/closing latch was added to the lid of the outer packaging of MC-LDPs to make it more difficult for young children to open. Between May and June 2012, the MC and OCs launched an educational campaign in major newspapers and magazines to promote safe use and storage of LDPs. Finally, since August 2012, MC-LDPs have begun to be marketed in opaque outer packaging. Subsequently, the Ministry decree of 18 December 2012,32 made the measures proposed by AISE mandatory. ${ }^{1}$ From January 2013, the LDPs see-through outer packaging had to be labelled with the precautionary statements "keep away from children" and 
"close the lid/bag properly" together with the corresponding standard icons or it had to be sold with a pamphlet reporting the same precautionary statement and corresponding icon. From June 2013, the outer packaging of the newly commercialised products needed to be opaque with a closure impeding the ability of young children to open the packaging - that is, requiring a coordinated action of both hands and more strength to open it, together with a yellow label reporting the above indicated precautionary statements and corresponding icons. Of note, in January 2014, LDPs still available in see-through outer containers had to be withdrawn from the market.

Our study aimed to compare the main characteristics of paediatric exposures to LDPs and TLDs that occurred in Italy between September 2010 and June 2015 and to analyse changes in exposure rates and trends after the introduction of preventive measures during the study period.

\section{METHODS}

\section{Data sources}

Each year, NPCCMi receives approximately 42000 reports of human exposure to different types of agents, accounting for more than $60 \%$ of all cases referred to the Italian PCCs. Most requests for toxicological assistance handled by NPCCMi are made by hospitals (60\% of cases) and the general public (30\% of cases) throughout Italy. Assistance with diagnosis and treatment of poisonings is provided by medical toxicologists, usually over the phone. For each case handled, the consulting toxicologist uses a standard form to collect the following categories of data: demographics, exposure characteristics (eg, substance/commercial product, route of exposure, circumstances, dose and latency between exposure and onset of clinical effects), signs and symptoms, treatment and outcome. Data on the quantity of MC-pods and OCs-pods sold were provided by the MC, expressed as million units sold/month between February 2010 and December 2014.

\section{Case selection criteria}

For this study, all cases of unintentional exposure to laundry detergents between 1 September 2010 and 30 June 2015 were extracted from the NPCCMi database. These cases were searched using NPCCMi hierarchical code of products, which qualifies the exposure of interest as non-pharmaceutical (first level), household cleaning product (second level) and laundry detergent (third level). ${ }^{33}$ The subsequent associated code levels are intended to provide the following pieces of information: type of detergent and physical form (fourth level) - that is, TLD, liquid/solid; LDP, liquid/half liquid and half solid, product brand name and company (fifth level). Unintentional exposure to laundry detergents was found in 3470 cases, of which 2958 $(85 \%)$ were in children aged $<5$ years and were included in the study. Patients aged $\geq 5$ years were excluded from the study. Among the included cases, 1150 patients were exposed to TLDs (39\%) and 1649 were exposed to LDPs (56\%). One hundred fifty-nine cases $(5 \%)$ were excluded from the study because it was unknown if the laundry detergent was a TLD or a LDP. Among patients exposed to LDPs, 1188 (72\%) were exposed to MC-LDPs and $461(28 \%)$ to OCs-LDPs.

\section{Variables}

The variables analysed included: site of case management (hospital/non-hospital), demographic characteristics (age and gender; month and year of exposure), route of exposure, clinical effects and treatments. The product companies were classified into two groups-MC, covering $100 \%$ to $50 \%$ of the Italian market during the study period, and OCs. Data collected for each symptomatic case were reviewed by one of the authors (FD), a clinical toxicologist, to evaluate the association between clinical effects and exposure. Additionally, severity of outcome was graded according to the Poisoning Severity Score, ${ }^{34}$ - that is, none-no signs/symptoms; low-mild, transient and spontaneously resolving signs/symptoms, including eye irritation/ redness, rash, skin redness/irritation, oral cavity irritation/ redness, emesis (one to three episodes), diarrhoea (one to three episodes), self-resolving cough, sore tongue/mouth/throat; moderate-pronounced or prolonged signs/symptoms, including corneal ulceration, skin erythema/burns, emesis (more than three episodes), diarrhoea (more than three episodes), persistent cough, difficulty in breathing not requiring intubation, burning sensation of the mouth, transient drowsiness/central nervous system depression; high-life-threatening signs/symptoms or resulting in significant residual disability or disfigurement, including oedema of epiglottis/glottis/pharynx/larynx, difficulty in breathing requiring intubation, persistent drowsiness/ central nervous system depression, corrosive injuries of the gastrointestinal tract, metabolic acidosis, melena; fatal-death as a result of exposure or of direct complications of the exposure effects; not associated-no signs/symptoms possibly related to the exposure; insufficient data-the available information is indicative of a causal relationship between exposure and an adverse health effect but it is inadequate for severity grading.

\section{Statistical methods and ethical considerations}

The characteristics of patients exposed to the two main categories of laundry detergents were compared by Pearson's $\chi^{2}$ test or Fisher's exact test. The following occurrence measures were calculated: mean number of cases of exposure/day by month, year and category of laundry detergent, mean number of cases of exposure to LDPs/million units sold by month, year and company - that is, MC vs OCs. Information on the quantity sold between September 2010 and December 2015 was provided by the MC. To determine whether an occurrence change had taken place during the study period, the series of rates estimates were analysed according to the procedure described by Taylor for performing a change-point analysis. ${ }^{35}$ This procedure iteratively uses a combination of cumulative sum charts (CUSUM) and bootstrapping analysis, which provides for each detected point a confidence level indicating how confident the analysis is that the change actually occurred, and a CI indicating how well the time of change point has been pinpointed. Changes at $95 \%$ or higher confidence level of rates calculated as number of patients exposed to LDPs/millions units sold by month and company were used to define pre- and post-change periods for subsequent analyses. The mean numbers of cases of exposure to LDPs/month observed in the pre- and post-change periods, adjusted by quantity sold, were compared using analysis of variance. Regression analysis was subsequently used to quantify the exposure period effect according to the change in the mean number of cases/month, along with its $95 \%$ CIs.

Further statistical analyses were carried out to check the sensitivity to different distributional assumptions-that is, Poisson regression, using the quantity sold as an offset. To account for variance heterogeneity, regression models were also used on transformed data. In particular, the square root transformation was used to stabilise the variance. Two logistic regression models were used to measure the effect of exposure to laundry detergents as a risk factor for clinical effects (none; at least one) and their severity (none/low severity; moderate/high severity), by maximum likelihood estimate of the ORs and the related 
95\% CIs, adjusted by age (<1 year; $1-2$ years; $3-4$ years) and exposure period (pre-change-point period; post-change-point period).

The analyses were performed using STATA statistic package V.11 and Taylor change-point analyzer (StataCorp, Stata Statistical Software: release 12. College Station, TX: StataCorp LP, 2011; Taylor W Change-Point Analyzer 2.0 shareware program. Libertyville, Illinois: Taylor Enterprises).

This study was approved by the ethical committee of Niguarda Hospital.

\section{RESULTS}

\section{General characteristics and management site}

The main characteristics of patients exposed to TLDs and LDPs are described in table 1.

The two groups exposed to either TLDs or LDPs showed different distribution by gender age, and route of exposure $(\mathrm{p}<0.001$, respectively). In comparison with patients exposed to TLDs, patients exposed to LDPs included a higher proportion of female subjects ( $48 \%$ vs $41 \%$ ), tended to be older, with a higher proportion of children aged 3 years $(18 \%$ vs $12 \%)$ or 4 years $(10 \%$ vs $5 \%)$, and were more often exposed via multiple routes $(12 \%$ vs $6 \%)$, mainly ingestion in combination with eye and/or skin (8\% vs 3\%). Children exposed to LDPs were more often managed at hospital (68\% vs 42\%, p<0.001).

Table 1 Characteristics of children aged $<5$ years and exposed to laundry detergents in Italy between September 2010 and June 2015

\begin{tabular}{|c|c|c|c|c|c|c|}
\hline \multirow{2}{*}{ Characteristics } & \multicolumn{2}{|l|}{ LDPs } & \multicolumn{2}{|l|}{ TLDs } & \multicolumn{2}{|l|}{ Total } \\
\hline & $\mathbf{n}$ & $\% \dagger$ & $\mathbf{n}$ & $\% \dagger$ & $\mathbf{n}$ & $\% \dagger$ \\
\hline \multicolumn{7}{|l|}{ Gender*** } \\
\hline Female & 791 & 48.0 & 470 & 40.9 & 1261 & 45.1 \\
\hline Male & 856 & 51.9 & 680 & 59.1 & 1536 & 54.9 \\
\hline Unknown & 2 & 0.1 & 0 & 0.0 & 2 & 0.1 \\
\hline \multicolumn{7}{|l|}{ Age (years) ${ }^{* *}$} \\
\hline$<1$ & 95 & 5.8 & 52 & 4.5 & 147 & 5.3 \\
\hline 1 & 621 & 37.7 & 489 & 42.5 & 1110 & 39.7 \\
\hline 2 & 484 & 29.4 & 415 & 36.1 & 899 & 32.1 \\
\hline 3 & 289 & 17.5 & 135 & 11.7 & 424 & 15.1 \\
\hline 4 & 160 & 9.7 & 59 & 5.1 & 219 & 7.8 \\
\hline \multicolumn{7}{|l|}{ Route of exposure ${ }^{* * *}$} \\
\hline Single route & 1452 & 88.1 & 1072 & 93.2 & 2524 & 90.2 \\
\hline Ingestion & 1363 & 82.7 & 1025 & 89.1 & 2388 & 85.3 \\
\hline Eye & 76 & 4.6 & 28 & 2.4 & 104 & 3.7 \\
\hline Skin & 13 & 0.8 & 19 & 1.7 & 32 & 1.1 \\
\hline Multiple routes & 197 & 11.9 & 73 & 6.3 & 270 & 9.6 \\
\hline Ingestion and eye & 84 & 5.1 & 17 & 1.5 & 101 & 3.6 \\
\hline Ingestion eye and skin & 27 & 1.6 & 8 & 0.7 & 35 & 1.3 \\
\hline Ingestion and skin & 28 & 1.7 & 9 & 0.8 & 37 & 1.3 \\
\hline Eye and skin & 54 & 3.3 & 36 & 3.1 & 90 & 3.2 \\
\hline Other & 4 & 0.2 & 3 & 0.3 & 7 & 0.3 \\
\hline Unknown & 0 & 0.0 & 5 & 0.4 & 5 & 0.2 \\
\hline \multicolumn{7}{|l|}{ Management site s** $^{* *}$} \\
\hline Hospital & 1123 & 68.1 & 477 & 41.5 & 1600 & 57.2 \\
\hline Private residence & 526 & 31.9 & 673 & 58.5 & 1199 & 42.8 \\
\hline
\end{tabular}

\section{Clinical effects and treatments}

As shown in table 2, patients exposed to LDPs more often had clinical effects $(75 \%$ vs $22 \%, \mathrm{p}<0.001)$, and developed moderate/high severity effects $(13 \%$ vs $<1 \%$ (based on one case of moderate severity), $\mathrm{p}<0.0001)$. No deaths associated with laundry detergent exposure were seen. Among symptomatic cases, those exposed to LDPs more often developed gastrointestinal $(76 \%$ vs $66 \%, \mathrm{p}<0.01)$ oropharyngeal $(27 \%$ vs $12 \%$, $\mathrm{p}<0.001)$ and respiratory $(19 \%$ vs $11 \%, \mathrm{p}<0.01)$ effects than those exposed to TLDs. A number of signs were observed only among patients exposed to LDPs, including lips/oral cavity oedema and de-epithelisation (7 cases, respectively), laryngospasm/bronchospasm (19 cases), lung sounds such as wet rales (14 cases) and stridor (7 cases), bronchial hypersecretion (11 cases), respiratory failure (6 cases), glottis/oesophagus caustic injuries/erosion (5 cases), glottis/epiglottis oedema (3 cases), chemical pneumonia (3 cases), corneal abrasion (22 cases) and rash (8 cases).

In both groups the vast majority of patients received at least one treatment (LDPs: 99\%; TLDs, 94\%), and, more specifically, at least a symptomatic treatment (LDPs: 92\%; TLDs: 84\%) (table 3). Patients exposed to LDPs were more frequently treated with $\mathrm{H}_{2}$ blockers ( $32 \%$ vs $\left.6 \%, \mathrm{p}<0.001\right)$, steroids $(4 \%$ vs $1 \%, \mathrm{p}<0.001)$, antibiotics $(3 \%$ vs $0.3 \%, \mathrm{p}<0.001)$ and fluids intravenous ( $2 \%$ vs $0.6 \%, \mathrm{p}<0.01)$.

In both groups, antidotal therapy referred only to dimethicone/simethicone administration, with a significantly higher percentage of patients treated among those exposed to LDPs (62\% vs $51 \%, \mathrm{p}<0.001)$.

None of the patients exposed to TLDs was given supportive care, while seven patients exposed to LDPs required support ventilation and one patient was intubated.

\section{Rate changes and trends}

The monthly mean number of patients/day exposed to TLDs compared with the two LDPs groups-that is, MC-LDPs and OCs-LDPs, is shown in figure 1A, B. A change is indicated by an interruption of the background colour. No change-points were identified for the mean number of patients/day exposed to TLDs (overall estimated average: 0.65 cases/day) (figure 1A, B). The mean number of patients/day exposed to MC-LDPs underwent a change in December 2012 (CI December 2012 to December 2012) at a confidence level of 100\% (figure 1A). Before the observed change the estimated average was 1.03 cases/day, while it became 0.36 cases/day in the post-change period. Three consecutive changes were observed for the mean number of patients/day exposed to OCs-LDPs (figure 1B). They included an upward change detected in April 2012 (CI April 2012 to April 2012) at a confidence level of 100\%, with estimated averages increasing from 0.24 cases/day (August 2011 to March 2012) to 0.53 cases/day (April to November 2012), and two subsequent rate decreases. The first one, identified in December 2012 (CI December 2012 to June 2013; confidence level: 98\%), indicated that between December 2012 and September 2013 the estimated average was reduced from 0.53 to 0.38 cases/day; the second one, identified in October 2013 (CI April 2013 to March 2014; confidence level: 98\%), indicated that between October 2013 and June 2015 the observed average was further reduced from 0.38 to 0.25 cases/day.

The change-point analysis based on the number of patients exposed to LDPs/million units sold by month and company is shown in figure 1C. The observed results confirmed an abrupt change of MC-LDP exposure rates in December 2012 (CI 
Table 2 Clinical effects associated with laundry detergents among children aged $<5$ years exposed in Italy between September 2010 and June 2015

\begin{tabular}{|c|c|c|c|c|c|c|}
\hline \multirow[b]{2}{*}{ Clinical effects } & \multicolumn{2}{|l|}{ LDPs } & \multicolumn{2}{|c|}{ TLDs } & \multicolumn{2}{|l|}{ Total } \\
\hline & $\mathrm{n}$ & $\% \dagger$ & $\mathrm{n}$ & $\% \dagger$ & $\mathbf{n}$ & $\% \dagger$ \\
\hline \multicolumn{7}{|c|}{ Association between exposure and clinical effects*** } \\
\hline None/not associated & 393 & 23.8 & 882 & 76.7 & 1275 & 45.6 \\
\hline Insufficient data & 23 & 1.4 & 18 & 1.6 & 41 & 1.5 \\
\hline Associated & 1233 & 74.8 & 250 & 21.7 & 1483 & 53.0 \\
\hline \multicolumn{7}{|l|}{ Severity of clinical effects*** } \\
\hline Low & 1076 & 87.3 & 249 & 99.6 & 1325 & 89.3 \\
\hline Moderate & 147 & 11.9 & 1 & 0.4 & 148 & 10.0 \\
\hline High & 10 & 0.8 & 0 & 0.0 & 10 & 0.7 \\
\hline \multicolumn{7}{|l|}{ Main clinical effects } \\
\hline Gastrointestinal ${ }^{* *}$ & 937 & 76.0 & 166 & 66.4 & 1103 & 74.4 \\
\hline Vomiting & 897 & 72.7 & 154 & 61.6 & 1051 & 70.9 \\
\hline Diarrhoea & 129 & 10.5 & 8 & 3.2 & 137 & 9.2 \\
\hline Abdominal pain & 26 & 2.1 & 4 & 1.6 & 30 & 2.0 \\
\hline Nausea & 23 & 1.9 & 8 & 3.2 & 31 & 2.1 \\
\hline Heartburn & 8 & 0.6 & 2 & 0.8 & 10 & 0.7 \\
\hline Oropharyngeal ${ }^{* * *}$ & 330 & 26.8 & 31 & 12.4 & 361 & 24.3 \\
\hline Hyperaemia oral cavity & 170 & 13.8 & 9 & 3.6 & 179 & 12.1 \\
\hline Irritation/pharyngeal pain & 140 & 11.4 & 14 & 5.6 & 154 & 10.4 \\
\hline Drooling & 108 & 8.8 & 5 & 2.0 & 113 & 7.6 \\
\hline Lips hyperaemia & 7 & 0.6 & 4 & 1.6 & 11 & 0.7 \\
\hline Lips/oral cavity oedema & 7 & 0.6 & 0 & 0.0 & 7 & 0.5 \\
\hline Lips/oral cavity de-epithelisation & 7 & 0.6 & 0 & 0.0 & 7 & 0.5 \\
\hline Respiratory** & 228 & 18.5 & 28 & 11.2 & 256 & 17.3 \\
\hline Cough & 208 & 16.9 & 25 & 10.0 & 233 & 15.7 \\
\hline Dyspnoea & 20 & 1.6 & 4 & 1.6 & 24 & 1.6 \\
\hline Laryngospasm/bronchospasm & 19 & 1.5 & 0 & 0.0 & 19 & 1.3 \\
\hline Stridor & 7 & 0.6 & 0 & 0.0 & 7 & 0.5 \\
\hline Wet rales & 14 & 1.1 & 0 & 0.0 & 14 & 0.9 \\
\hline Bronchial hypersecretion & 11 & 0.9 & 0 & 0.0 & 11 & 0.7 \\
\hline Respiratory failure & 6 & 0.5 & 0 & 0.0 & 6 & 0.4 \\
\hline $\begin{array}{l}\text { Glottis/oesophagus caustic } \\
\text { injuries/erosion }\end{array}$ & 5 & 0.4 & 0 & 0.0 & 5 & 0.3 \\
\hline Glottis/epiglottis oedema & 3 & 0.2 & 0 & 0.0 & 3 & 0.2 \\
\hline Chemical pneumonia & 3 & 0.2 & 0 & 0.0 & 3 & 0.2 \\
\hline Ocular & 209 & 17.0 & 44 & 17.6 & 253 & 17.1 \\
\hline Hyperaemia & 198 & 16.1 & 39 & 15.6 & 237 & 16.0 \\
\hline Irritation/pain & 184 & 14.9 & 34 & 13.6 & 218 & 14.7 \\
\hline Lachrymation & 35 & 2.8 & 3 & 1.2 & 38 & 2.6 \\
\hline Photophobia & 24 & 1.9 & 2 & 0.8 & 26 & 1.8 \\
\hline Corneal abrasion & 22 & 1.8 & 0 & 0.0 & 22 & 1.5 \\
\hline Ptosis & 19 & 1.5 & 1 & 0.4 & 20 & 1.3 \\
\hline Dermal & 76 & 6.2 & 10 & 4.0 & 86 & 5.8 \\
\hline Hyperaemia & 36 & 2.9 & 4 & 1.6 & 40 & 2.7 \\
\hline Oedema & 20 & 1.6 & 1 & 0.4 & 21 & 1.4 \\
\hline Rash & 8 & 0.6 & 0 & 0.0 & 8 & 0.5 \\
\hline Macule & 5 & 0.4 & 1 & 0.4 & 6 & 0.4 \\
\hline
\end{tabular}

${ }^{* *} \mathrm{p}<0.01 ;{ }^{* * *} \mathrm{p}<0.001$

tThe column percentages referring to the 'association between exposure and clinical effects' were calculated using the total number of patients exposed to LDPs $(n=1649)$, TLDs $(n=1150)$ and total $(n=2799)$, respectively; the column percentages referring to 'severity of clinical effects' and the 'main clinical effects' were calculated using the total number of patients with associated clinical effects exposed to LDPs $(n=1233)$, TLDs $(n=250)$ and total $(n=1483)$, respectively. The percentages referring to 'main clinical effects' may not add up to $100 \%$ because some patients had more than one clinical effect.

LDP, laundry detergent pod; TLD, traditional laundry detergent.
Table 3 Treatments reported for children aged $<5$ years and exposed to laundry detergents in Italy between September 2010 and June 2015

\begin{tabular}{|c|c|c|c|c|c|c|}
\hline \multirow[b]{2}{*}{ Treatments } & \multicolumn{2}{|l|}{ LDPs } & \multicolumn{2}{|l|}{ TLDs } & \multicolumn{2}{|l|}{ Total } \\
\hline & $\mathbf{n}$ & $\% \dagger$ & $\mathbf{n}$ & $\% \dagger$ & $\mathbf{n}$ & $\% \dagger$ \\
\hline \multicolumn{7}{|l|}{ At least one treatment*** } \\
\hline No & 18 & 1.1 & 74 & 6.4 & 92 & 3.3 \\
\hline Yes & 1631 & 98.9 & 1076 & 93.6 & 2707 & 96.7 \\
\hline Symptomatic treatment ${ }^{* * *}$ & 1522 & 92.3 & 962 & 83.7 & 2484 & 88.7 \\
\hline Antacids/mucosal protection & 1396 & 84.7 & 942 & 81.9 & 2338 & 83.5 \\
\hline H2 blockers*** & 521 & 31.6 & 69 & 6.0 & 590 & 21.1 \\
\hline Steroids*** & 66 & 4.0 & 13 & 1.1 & 79 & 2.8 \\
\hline Antibiotics*** & 49 & 3.0 & 4 & 0.3 & 53 & 1.9 \\
\hline Fluids intravenous* * & 37 & 2.2 & 7 & 0.6 & 44 & 1.6 \\
\hline Other** & 44 & 2.7 & 12 & 1.0 & 56 & 2.0 \\
\hline Antidote & 1029 & 62.4 & 587 & 51.0 & 1616 & 57.7 \\
\hline Dimethicone/simethicone $e^{* * *}$ & 1029 & 62.4 & 587 & 51.0 & 1616 & 57.7 \\
\hline $\begin{array}{l}\text { Decontamination/absorption } \\
\text { prevention }^{\star * *}\end{array}$ & 295 & 17.9 & 103 & 9.0 & 398 & 14.2 \\
\hline Dilute/irrigate/wash-ocular ${ }^{* * *}$ & 162 & 9.8 & 56 & 4.9 & 218 & 7.8 \\
\hline Emesis/ipecac ${ }^{* * *}$ & 109 & 6.6 & 20 & 1.7 & 129 & 4.6 \\
\hline Dilute/irrigate/wash—dermal & 62 & 3.8 & 37 & 3.2 & 99 & 3.5 \\
\hline Activated charcoal & 4 & 0.2 & 1 & 0.1 & 5 & 0.2 \\
\hline Supportive care & 7 & 0.4 & 0 & 0.0 & 7 & 0.3 \\
\hline Artificial ventilation & 6 & 0.4 & 0 & 0.0 & 6 & 0.2 \\
\hline Intubation & 1 & 0.1 & 0 & 0.0 & 1 & 0.0 \\
\hline Unknown & 3 & 0.2 & 1 & 0.1 & 4 & 0.1 \\
\hline
\end{tabular}

October 2012 to December 2012; confidence level: 100\%). In the pre-change-point period the estimated average was 1.88 cases/million units sold, while in the post-change-point period (December 2012 to December 2014) it was reduced to 0.86 cases/million units sold. No change was detected for OCs-LDP exposure rates (overall estimated average: 0.95 cases/million units sold).

Analysis of variance performed taking into account the quantity of LDPs sold, confirmed that in the post-change-point period-that is, between December 2012 and December 2014, there was a statistically significant reduction in the mean number of patients exposed to MC-LDPs, accounting for -19.6 cases/month (95\% CI -23.2 to $-16.1, \mathrm{p}<0.0001)$. The sensitivity analysis supported the normal based inference (Poisson period coefficient $=-0.77, \mathrm{p}<0.001)$. However, when using the transformed data to take into account the data heterogeneity of variance, the statistical significance of the period effect was reduced (Poisson period coefficient $=-0.26, \mathrm{p}=0.054$ ).

\section{Risk analyses of clinical effects and their severity}

The logistic regression analysis carried out on all patients exposed to laundry detergents (table 4, model 1 ) showed that the odds of having at least one clinical effect, adjusted by exposure period and age, was similarly increased among patients exposed to MC-LDPs (OR=10.5; 95\% CI 8.6 to 12.8$)$ and 
Figure 1 Trends of monthly mean number of cases/day exposed to major company (MC)-laundry detergent pods (LDPs) versus traditional laundry detergents (TLDS) (A); other companies (OCs)-LDPs versus TLDs (B) and trends of number of cases/million caps sold exposed to MC-LDPs and OCs-LDPs (C).
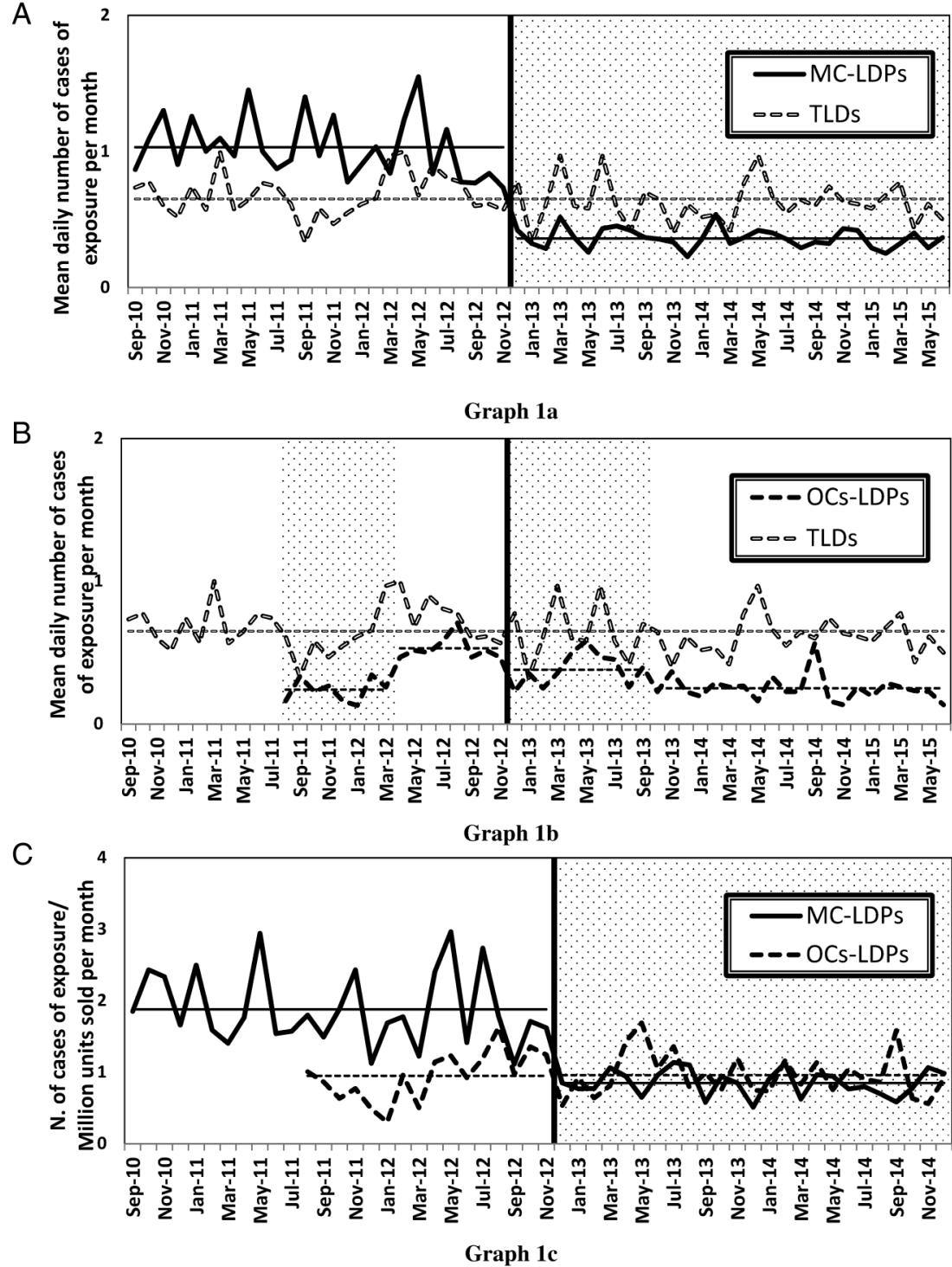

OCs-LDPs (OR=11.3; 95\% CI 8.8 to 14.7$)$ in comparison with TLDs. The analysis focusing only on patients exposed to LDPs (table 4, model 2) showed that those exposed to MC-LDPs were more likely $(\mathrm{OR}=1.8 ; 95 \% \mathrm{CI} 1.2$ to 2.7$)$ to develop moderate/ high severity clinical effects in comparison with OCs-LDPs. Furthermore, the odds of having moderate/high severity effects was four times higher for children aged $<1$ year than for those aged $3-4$ years (reference group) $(\mathrm{OR}=3.9 ; 95 \% \mathrm{CI} 2.2$ to 7.0$)$.

\section{DISCUSSION}

The results of this study corroborate findings from previous investigations showing that paediatric exposure to LDPs are more hazardous than those to TLDs. ${ }^{2-31}$

The main characteristics of paediatric patients exposed to LDPs and TLDs in Italy were similar to those reported in a previous study based on data from the US National Poison Data System. ${ }^{30}$ In particular, both studies show that among patients exposed to LDPs the percentages of those aged 3 and 4 years, exposed via multiple routes, managed at a hospital and with clinical effects are higher than those reported for TLDs.
In both countries children exposed to LDPs have higher odds of experiencing one or more clinical effect than those exposed to TLDs. The OR based on the Italian data $(\mathrm{OR}=10.8 ; 95 \% \mathrm{CI}$ 9.0 to 12.9 ) was more than twice that reported in the US study $(\mathrm{OR}=3.9 ; 95 \%$ CI 3.7 to 4.1$)$. This observation might be explained by several factors, including differences in the population served, ${ }^{33} 36$ pod users' behaviour and products on the market. The Italian study also highlighted a higher odds of having high severity effects for patients exposed to MC-LDPs than for those exposed to OCs-LDPs. This observation deserves particular attention since it might be related to differences in soluble packaging and/or intrinsic toxicity of mixtures.

During the study the number of patients exposed to TLDs was stable (0.65 cases/day), whereas a sharp, statistically significant decrease of exposure to MC-LDPs was seen in December 2012. The estimated values were reduced from 1.03 cases/day and 1.88 cases/million units sold (observed between September 2010 and November 2012) to 0.36 cases/day (observed between December 2012 and June 2015), and 0.86 cases/million units (observed between December 2012 and December 2014). In December 2012 a statistically significant reduction of the 
Table 4 Logistic regression models for clinical effects (model 1) and their severity (model 2) after exposure to laundry detergents

\begin{tabular}{|c|c|c|c|c|}
\hline $\begin{array}{l}\text { Model } 1 \\
\text { Including all patients exposed to laundry detergents }\end{array}$ & $\begin{array}{l}\text { Cases } \\
\text { (n) }\end{array}$ & $\begin{array}{l}\text { At least one } \\
\text { clinical effect } \\
(\%)\end{array}$ & $\begin{array}{l}\text { Unadjusted OR } \\
(95 \% \mathrm{Cl})\end{array}$ & $\begin{array}{l}\text { Adjusted OR } \\
(95 \% \mathrm{Cl})\end{array}$ \\
\hline \multicolumn{5}{|l|}{ Age (years) } \\
\hline$<1$ & 147 & 61.9 & $1.2(0.8$ to 1.7$)$ & 1.4 (0.9 to 2.2$)$ \\
\hline $1-2$ & 2009 & 50.7 & 0.7 (0.6 to 0.9$)$ & $1.0(0.8$ to 1.3$)$ \\
\hline $3-4$ & 643 & 58.2 & 1.0 & 1.0 \\
\hline \multicolumn{5}{|l|}{ Laundry detergent } \\
\hline TLDs & 1150 & 21.7 & 1.0 & 1.0 \\
\hline MC-LDPs & 1188 & 74.3 & 10.4 (8.6 to 12.6$)$ & 10.5 (8.6 to 12.8$)$ \\
\hline OCs-LDPs & 461 & 75.9 & $11.4(8.8$ to 14.7$)$ & 11.3 (8.8 to 14.7$)$ \\
\hline \multicolumn{5}{|l|}{ Exposure period } \\
\hline September 2010-November 2012 & 1593 & 55.7 & 1.0 & 1.0 \\
\hline December 2012-June 2015 & 1206 & 49.3 & $0.8(0.7$ to 0.9$)$ & $1.0(0.9$ to 1.3$)$ \\
\hline $\begin{array}{l}\text { Model } 2 \\
\text { Including patients exposed to LDPs }\end{array}$ & $\begin{array}{l}\text { Cases } \\
(\mathrm{n})\end{array}$ & $\begin{array}{l}\text { Moderate/high severity } \\
\text { outcomes }(\%)\end{array}$ & $\begin{array}{l}\text { Unadjusted OR } \\
(95 \% \mathrm{Cl})\end{array}$ & $\begin{array}{l}\text { Adjusted OR } \\
(95 \% \mathrm{Cl})\end{array}$ \\
\hline \multicolumn{5}{|l|}{ Age (years) } \\
\hline$<1$ & 95 & 25.3 & $3.9(2.2$ to 6.9$)$ & $3.9(2.2$ to 7.0$)$ \\
\hline $1-2$ & 1105 & 8.8 & $1.1(0.7$ to 1.6$)$ & $1.1(0.8$ to 1.7$)$ \\
\hline $3-4$ & 449 & 8.0 & 1.0 & 1.0 \\
\hline \multicolumn{5}{|l|}{ Laundry detergent } \\
\hline OCs-LDPs & 461 & 6.9 & 1.0 & 1.0 \\
\hline MC-LDPs & 1188 & 10.5 & $1.6(1.1$ to 2.4$)$ & $1.8(1.2$ to 2.7$)$ \\
\hline \multicolumn{5}{|l|}{ Exposure period } \\
\hline September 2010-November 2012 & 1033 & 8.7 & 1.0 & 1.0 \\
\hline December 2012-June 2015 & 616 & 10.9 & 1.3 (0.9 to 1.8$)$ & 1.5 (1.0 to 2.1$)$ \\
\hline
\end{tabular}

LDP, laundry detergent pod; MC, major company; OCs, other companies; TLD, traditional laundry detergent.

number of patients exposed daily to OCs-LDPs was also detected, reducing from 0.53 cases/day (observed between April and November 2012) to 0.38 cases/day (observed between December 2012 and September 2013). A further statistically significant reduction occurred in October 2013, when the estimated daily number of cases was reduced to 0.25 cases/day.

The initial changes seen in December 2012 occurred 4 months after the introduction of opaque outer packaging by the MC for the majority of LDPs marketed in Italy. This action might have been taken by some of the OCs at the same time since a decrease of the number of patients exposed to OCs/day was also detected. Previous preventive measures, including an information campaign for safe use of LDCs, launched between May and June 2012, and improvement of the outer packaging lid to make it more difficult for children to open, started in January 2012, were not followed by any detectable effect on exposure frequency. The second change, specifically with reference exposure to OCs-LDPs, occurred in Italy 5 months after it became compulsory to produce the new products in opaque outer-packaging with a closure impeding the ability of young children to open it. ${ }^{32}$ The available observations suggest that reducing the visibility of MC-LDPs effectively prevents young children from exposures, whereas other preventive measures seem to be poorly effective if the product is easily visible.

Exposures to LDCs are more frequently associated with moderate/high severity clinical effects than exposure to TLDs, and their attractiveness to children and intrinsic toxicity remains a major concern for prevention of hazardous exposures and injuries.
Like studies based on data from PCCs, our investigation has a number of limitations. First, it relies on cases voluntarily submitted to NPCCMi, representing an unknown proportion of those actually occurring in the served population. Information is mainly collected during the telephone call while the PCC specialist is providing diagnosis and treatment recommendations; this implies that systematic differences may occur in data collection for cases of higher severity owing to the stress of management. Nevertheless, PCCs are the most informative source for poisoning and can raise an alert and guarantee surveillance of specific exposures.

About $5 \%$ of cases initially extracted from the NPCCMi database were excluded from the study because the type of laundry detergent patients were exposed to was unknown. Among these cases, $77 \%$ were asymptomatic and the remaining $23 \%$ reported low severity outcomes. Distributions by age and site of management were similar to those observed for TLDs, suggesting that most of these patients were exposed to this type of detergent.

Two years after the introduction in Italy of obscured outer packaging for LDCs, the same measure was made compulsory in Europe,${ }^{37}$ together with other requirements for soluble packaging, including addition of an aversive agent to discourage children from consuming the product, ensuring the pods retained their liquid content for at least $30 \mathrm{~s}$ when placed in water at $20^{\circ}$ $\mathrm{C}$ and resisted a certain degree of standard mechanical compression.

Surveillance of LDP-related cases identified by national PCCs are needed to evaluate the effect of the new measures recently made compulsory in Europe and adopted voluntarily in the USA. $^{30}$ 


\section{What is already known on the subject}

- Previous investigations have shown that laundry detergents in pods have the potential to cause corrosive eye damage, pulmonary toxicity and serious laryngopharyngeal injuries in young children.

- Prevention of hazardous exposures to these products remains a major concern.

\section{What this study adds}

- Making these products less visible through the adoption of opaque outer packaging is likely to reduce the occurrence of exposure to pods.

- Further efforts are needed to reduce attractiveness to children of laundry detergents in pods and reduce their ability to cause injuries and poisoning following exposure.

Acknowledgements The authors are very grateful to Dr Ehi Idahosa-Taylor for paper revision and suggestions.

Contributors LS developed the research proposal, planned the study design and the analysis, drafted and edited the paper; FG and LL contributed to planning the analysis, carried out data quality control, statistical analysis and contributed to drafting and editing of the paper; $\mathrm{AC}$ and FS collected the data and contributed to editing of the paper. FD was responsible for data collection, assessment of clinical effects severity and contributed to developing the research proposal, the study design and edited the paper.

Funding The study was partially supported by the Italian Ministry of HealthNational Centre for Diseases Prevention and Control (CCM) program for surveillance of domestic incidents (Fasc. 3M61).

Competing interests None declared.

Ethics approval Ethical committee of the Niguarda Hospital.

Provenance and peer review Not commissioned; externally peer reviewed.

Data sharing statement Further data on patients aged 5+, accounting for about $19 \%$ of the detected exposures, are available. These data are included in the analyses presented as abstracts at the International Congress of the European Association of Poisons Centres and Clinical Toxicologists. 22 25

Open Access This is an Open Access article distributed in accordance with the Creative Commons Attribution Non Commercial (CC BY-NC 4.0) license, which permits others to distribute, remix, adapt, build upon this work non-commercially, and license their derivative works on different terms, provided the original work is properly cited and the use is non-commercial. See: http://creativecommons.org/ licenses/by-nc/4.0/

\section{REFERENCES}

1 A.I.S.E. Product Stewardship Programme for Liquid Laundry Detergent Capsules. https://www.aise.eu/our-activities/product-stewardship-programmes/liquid-detergentcapsules/aise-product-stewardship-programme-for-liquid-detergent-capsules-032015. aspx (accessed 1 Feb 2017)

2 Horgan N, McLoone E, Lannigan B, et al. Eye injuries in children: a new household risk. Lancet 2005:336:547-8.

3 Fayers T, Munneke R, Strouthidis NG. Detergent capsules causing ocular injuries in children. J Pediatr Ophthamol Strabismus 2006:43:250-1.

4 Mathew RG, Kennedy K, Corbett MC. Eyes and alkalis. Wave of paediatric eye injuries from liquid detergent capsules. BMJ 2010;340:c1186.

5 Mathieu-Nolf M, Deheul S, Nisse P. Liquid detergent capsules: a new risk [abstract]. Clin Toxicol (Phila) 2007:45:386.

6 Williams H, Moyns E, Bateman DN, et al. Hazard of household cleaning products: a study undertaken by the UK National Poisons Information Service. Clin Toxicol (Phila) 2012;50:770-5.

7 Williams H, Bateman DN, Thomas SHL, et al. Exposure to liquid detergent capsules: a study undertaken by the UK National Poisons Information Service. Clin Toxicol (Phila) 2012;50:776-80
8 Williams $\mathrm{H}$, Jones $\mathrm{S}$, Wood $\mathrm{K}$, et al. Reported toxicity in 1486 liquid detergent capsule exposures to the UK National Poisons Information Service 2009-2012, including their ophthalmic and CNS effects. Clin Toxicol (Phila) 2014;52:136-40.

9 Cooper GA, Thomson JP. Ingestion of liquidtab contents by a one-year-old child [abstract]. Clin Toxicol (Phila) 2006;44:707-8.

10 Wood KL, Thompson JP. Liquidtabs-a thorough and comprehensive review of the UK national data [abstract]. Clin Toxicol (Phila) 2009;47:459.

11 Fraser L, Wynne D, Clement WA, et al. Liquid detergent capsule ingestion in children: an increasing trend. Arch Dis Child 2012;97:1007.

12 Scheneir $A B$, Rentmeester $L$, Clark RF, et al. Toxicity following laundry detergent pod ingestion. Pediatr Emerg Care 2013;29:741-2.

13 Beuhler MC, Gala PK, Wolfe HA, et al. Laundry detergent "pod" ingestions: a case series and discussion of recent literature. Pediatr Emerg Care 2013;29:743-7.

14 Celentano A, Sesana F, Settimi L, et al. Severe respiratory and esophageal effects resulting from ingestion of unit dose liquid laundry detergents: a case report [abstract]. Clin Toxicol (Phila) 2013;51:311.

15 Heppner J, Huntinghton S, Vohora R, et al. Serious adverse effects from single use detergent sacs: report from a statewide poison system [abstract]. Clin Toxicol 2013:51:604.

16 Stromberg PE, Burt MH, Rutherfoord Rose S, et al. Airway compromise in children exposed to single-use laundry detergent pods: confirmation of toxicity in a large case series [abstract]. Clin Toxicol (Phila) 2013;51:604.

17 Kastanje $R$, Pöld $K$, Peet $A$, et al. Development of respiratory acidosis following the ingestion of a liquid detergent capsule by a boy aged 1 year 10 months: a case report [abstract]. Clin Toxicol (Phila) 2014;52:415.

18 Nguyet V, Kramer S, Wightman R, et al. Laundry detergent causing esophageal and gastric injuries in adult [abstract]. Clin Toxicol (Phila) 2014;52:427.

19 Lasnier O, El-Hadad C, Superstein R. Two cases of corneal abrasions in children exposed to liquid detergent capsules. Can I Ophthalmol 2013; 48:e29-30.

20 Valdez AL, Casavant MJ, Spiller HA, et al. Pediatric exposure to laundry detergent pods. Pediatrics 2014;134:1127-35.

21 Celentano A, Sesana F, Milanesi G, et al. Ocular toxicity of unit dose liquid laundry detergents: a case report [abstract]. Clin Toxicol (Phila) 2013;51:311.

22 Celentano A, Sesana F, Settimi L, et al. Skin injuries resulting from accidental exposure to unit dose liquid laundry detergents: a case report [abstract]. Clin Toxicol (Phila) 2013:51:311-12

23 Cole JB, Orozco BS, Setzer SC, et al. The princess and the pod: a unique laundry detergent complication [abstract]. Clin Toxicol (Phila) 2013:51:605.

24 Russell JL, Wiles DA, Kenney B, et al. Significant chemical burns associated with dermal exposure to laundry pod detergent. J Med Toxicol 2014;10:292-4.

25 Celentano A, Sesana F, Settimi L, et al. Accidental exposures to liquid detergents capsules [abstract]. Clin Toxicol (Phila) 2012;50:353.

26 Center for Disease Control and Prevention (CDC). Health hazard associated with laundry detergent pods-United States, May-June 2012. MMWR Morb Mortal Wkly Rep 2012:6:825-9.

27 Huntington S, Heppner J, Vohra R, et al. Serious adverse effects from single-use detergent sacs: report from a U.S. Statewide poison control system. Clin Toxicol (Phila) 2014;52:220-5.

28 Mowry JB, Spyker DA. Comparison of 15,329 unit dose and 12,599 non-unit dose pediatric laundry detergent exposures using US National Poison Data System data: 2012-2013 [abstract]. Clin Toxicol (Phila) 2014;52:335.

29 Yin S, Behrman A, Colvin J. Laundry pack exposures in children $0-5$ years evaluated at a single pediatric institution. J Pediatr Emerg Med 2015;48:506-72.

30 Davis MG, Casavant MJ, Spiller HA, et al. Pediatric exposures to laundry and dishwasher detergents in the United States: 2013-2014. Pediatrics 2016;137: e20154529.

31 Swain TA, McGwin G Jr, Griffin R. Laundry pod and non-pod detergent related emergency department visits occurring in children in the USA. Inj Prev 2016:22:396-9

32 Italian Ministry of Health. Administrative circular of 4 July 2013. Safe use of concentrated liquid detergents in water soluble caps. http://www.trovanorme.salute. gov. it/norme/renderNormsanPdf?anno $=0 \&$ codLeg $=46480 \&$ parte $=1 \% 20 \&$ serie (accessed 25 Jul 2016)

33 Settimi L, Davanzo F, Urbani E, et al. National informative system for surveillance of toxic exposures and poisonings: cases identified in 2011. 6th Annual Report. Roma: Istituto Superiore di Sanità. Rapporti ISTISAN 2015; $15 / 28$ (In Italian).

34 Persson HE, Sjöberg GK, Haines JA, et al. Poisoning severity score. Grading of acute poisoning. J Toxicol Clin Toxicol 1998;36:205-13.

35 Taylor W. Change-point analysis: a power tool for detecting changes. Libertyville: Taylor Enterprises, 2000. http://www.variation.com/files/articles/changepoint.pdf (accessed 25 Jul 2016).

36 Mowry JB, Spyker DA, Brooks DE, et al. 2014 Annual Report of the American Association of Poison Control Centers' National Poison Data System (NPDS): 32nd Annual Report. Clin Toxicol (Phila) 2015:53:962-1147.

37 Commission Regulation (EU). No 1297/2014 of 5 December 2014. OJ L 350 6.12.2014. http://eur-lex.europa.eu/legal-content/EN/TXT/PDF/?uri=OJ:JOL 2014 350_R_0001 (accessed 26 Jul 2016). 